\title{
Multiple Orientation Circuits Converging on the Pd7 Cells in Tritonia diomedea
}

\author{
L. G. Abraçado \\ Instituto de Ciências Biomédicas, Universidade Federal do Rio de Janeiro, CCS Bloco F, Cidade Universitária, \\ 21941-902 Rio de Janeiro, RJ, Brazil \\ Correspondence should be addressed to L. G. Abraçado, leidaabracado@hotmail.com
}

Received 20 March 2012; Accepted 24 April 2012

Academic Editors: V. N. Binhi and A. Lisi

Copyright ( 2012 L. G. Abraçado. This is an open access article distributed under the Creative Commons Attribution License, which permits unrestricted use, distribution, and reproduction in any medium, provided the original work is properly cited.

Magnetoreception is a sophisticated orientation mechanism, involving a magnetoreceptor connected to the nervous system with signal amplification. The mollusk Tritonia diomedea is a good model to investigate the behavioral and neural responses to the magnetic field. The mollusk inhibits all unnecessary activities and focuses on an available cue during orientation. Although Pd7 cells are inhibited by magnetic pathway, it was excited by another stimulus, water streams plus food odor. Two sensory pathways connected to Pd7 through the same or different circuits were tested. The action potential activity through Pd7 was compared in these different stimulations. The changes in Pd7 activity indicate a response of enhanced electrical activity to water streams plus food odor stimulus, and Pd7 activity can be excited by at least one of these stimuli. These results indicate an inverse relationship between magnetic orientation and feeding.

\section{Introduction}

Animals use several orientation mechanisms, including those based on the geomagnetic field. Magnetoreception is a sophisticated orientation mechanism, involving a magnetoreceptor connected to the nervous system with signal amplification. The mollusk Tritonia diomedea is a good model to investigate the behavioral and neural responses to the magnetic field because it possesses individually identifiable neurons that are easily accessible while the animal performs a wide repertoire of behaviors [1,2]. Previous experiments showed that Tritonia diomedea can use the Earth's magnetic field as an orientation cue [3]. Furthermore, the brain system of the animal is accessible to neurophysiologic investigation [4-6]. Six large, individually identifiable neurons in the brain of Tritonia diomedea are known to respond with altered electrical activity to changes in earth-strength magnetic fields [4-6], and previous results provide evidence that the Pd5 and Pd6 cells directly control or modulate the activity of cilia involved in locomotion [4-6]. Experiments with Pd5 neurons from Tritonia diomedea excited by earth-strength magnetic stimuli showed that the afferent pathway includes pedal nerves 2 and 3 and that $\mathrm{Pd} 5$ is likely to play a motor role in the orientation of the animal to magnetic fields [7]. But the function of pedals 7 during Tritonia diomedea crawling is already unknown.

The Pd7 neurons are inhibited by magnetic stimuli whereas the Pd5 and Pd6 neurons are excited [4-6]. The neurons Pd7 have neuritis in nerves that project to regions of the anterior body wall, oral veil, and mouth [5], and the Pd5 and Pd6 neurons have axons in nerves projecting to the foot $[4,6]$. In addition, Pd5, Pd6, and Pd7 have some common synaptic inputs, as indicated by synchronous postsynaptic potentials, and also independent inputs.

On the other hand, Wyeth and Willows [8] showed that odors that can be detected by rhinophores mediate orientation to flow. And Pd7 innervates CeN3 that projects to the organ of Hancock. These organs use their cilia to create water currents, bringing odor to chemoreceptors; see Figure 1.

In the present study, the possibility of the slug inhibits all unnecessary activities and focuses on an available cue during which orientation was investigated. Although Pd7 is inhibited by magnetic pathway, it could be excited by another stimulus, as water streams or food odor. Two sensory pathways connected to $\mathrm{Pd} 7$ through the same or different 


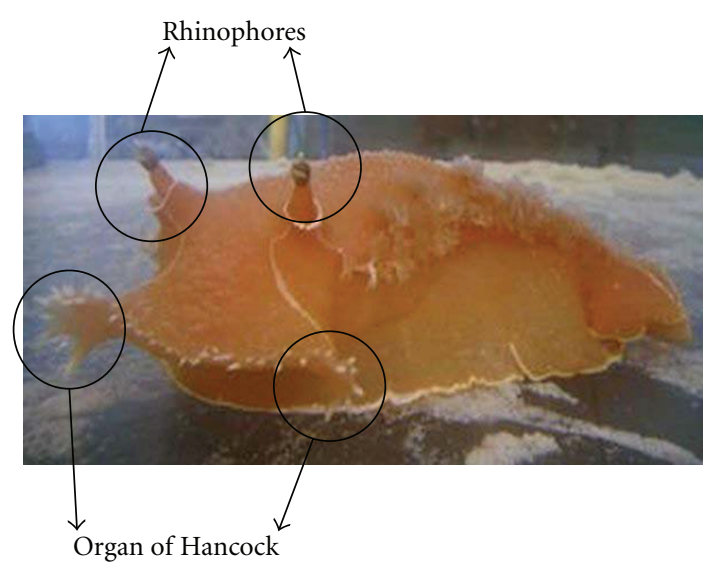

Figure 1: The mollusk Tritonia diomedea on the tanks with seawater. Details show the rhinophores and Organ of Hancock.

circuits were tested. In the first case the magnetic and chemorheotactic receptor would stimulate the central nervous system, the stimulus from magnetic information would send a message to inhibited $\mathrm{Pd} 7$ neuron motor, and chemorheotactic would send a message through a different circuit to the excited Pd7 neuron motor. In the second case both pieces of information would send the message through the same circuit to the inhibited Pd7 neuron motor. Based on previous results, a semi-intact, whole animal preparation [5] was used to investigate the functions of Pd7. The action potential activity through $\mathrm{Pd} 7$ was compared in these different stimulations.

\section{Materials and Methods}

2.1. Samples. Tritonia diomedea were trawled from Bellingham Bay, Washington, or collected using SCUBA near Tacoma, Washington, USA. The animals were taken to the University of Washington, Friday Harbor Laboratories, Friday Harbor, Washington and kept in tanks with seawater flow at $11^{\circ} \mathrm{C}$. Animals were fed with sea pens (Ptilosarcus gurneyi).

2.2. Semi-Intact Preparation. To record activity in the $\mathrm{Pd} 7$ neuron, a semi-intact preparation described by Willows et al. [2] was used. A small incision was made on the dorsal side of the animal, posterior to the brain, up to midway between the two rhinophores. The animal was suspended in an acrylic tank to further enlarge the incision and expose the brain. The brain was then pinned to the platform and slightly elevated out of the body cavity to allow easier access to the neurons for penetration (Figure 2(a)). The cells were identified by location in the pedal ganglion based on size, color, and location [4-6]. Pd7 cells were impaled with glass microelectrodes filled with $2 \mathrm{~mol} 1: 1 \mathrm{KCl}$ and 3 mol $1: 1 \mathrm{KAc}$ (Figure 2(b)); its activity was amplified by AXOCLAMP-2A and digitalized by PowerLab 4/20T (AD Instruments). Seven animals were stimulated directly with seawater containing odors from sea pens (Ptilosarcus gurneyi) and changes in

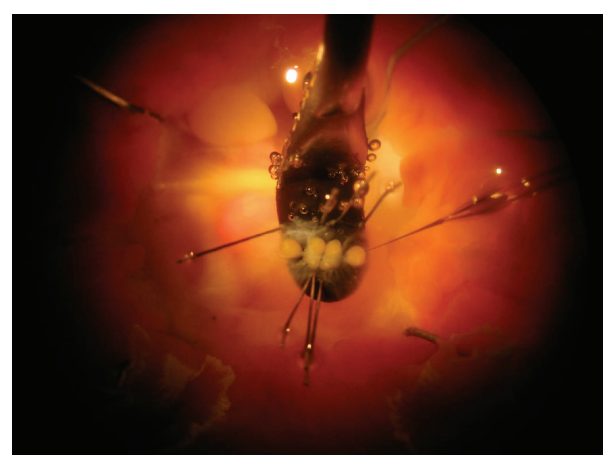

(a)

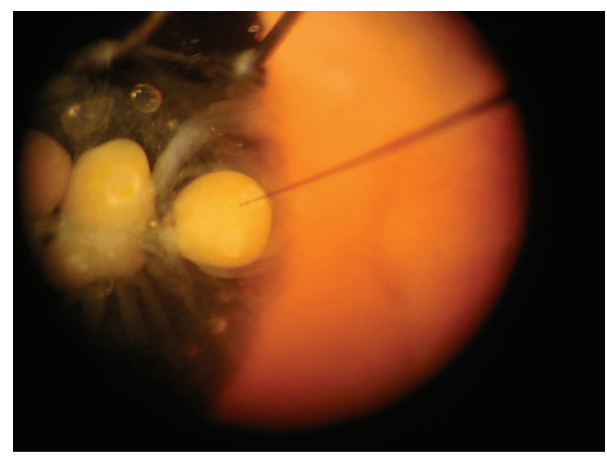

(b)

Figure 2: (a) Tritonia diomedea brain pinned to the platform and slightly elevated out of the body cavity. (b) Pd7 cells were impaled with glass microelectrodes.

the ambient magnetic field. After impaled RPd7 or LPd7, a period of one hour was given to stabilize the action potential activity. On sequence, 15 minutes of baseline period followed by 30 minutes of magnetic stimulus period [5, 7] or 15 minutes of baseline followed by around 13 minutes of water streams plus odor stimulus was performed. These two stimuli were applied in different order.

2.3. Magnetic Field Stimulus. The dissection chamber is located in the center of a Merritt 4-coil system. This coil system was used to rotate the magnetic field $60^{\circ}$ clockwise during experiments. Alterations to the total magnetic intensity and inclination angles were minimal [5].

2.4. Water Streams and Food Odor Stimulus. Sea pens (Ptilosarcus gurneyi) were kept in seawater for around 2 hours. The water with food odor was led through a hose to the animal (Figure 3). The water streams cover the oral veil, mouth, rhinophores, and the organ of Hancock.

2.5. Statistical Analyses. The software Microcal Origin 6.0 was used to plot graphic and performed statistical analyses. Statistical analyses were carried out using paired $t$-test (at the 0.05 level). 
TABle 1: The mean value and standard deviation of the spikes per minute Pd7 cells activity without stimuli and when stimulated with magnetic field changes or water streams plus food odor.

\begin{tabular}{lccc}
\hline Recordings & All animals & Larger animals & Smaller animals \\
& & $12 \pm 2 \mathrm{~cm}$ & $6 \pm 1 \mathrm{~cm}$ \\
\hline Baseline & $16 \pm 10$ & $23 \pm 6$ & $7 \pm 3$ \\
Magnetic field & $8 \pm 5$ & $11 \pm 4$ & $5 \pm 5$ \\
Water streams plus food odor & $22 \pm 14$ & $32 \pm 10$ & $9 \pm 1$ \\
\hline
\end{tabular}

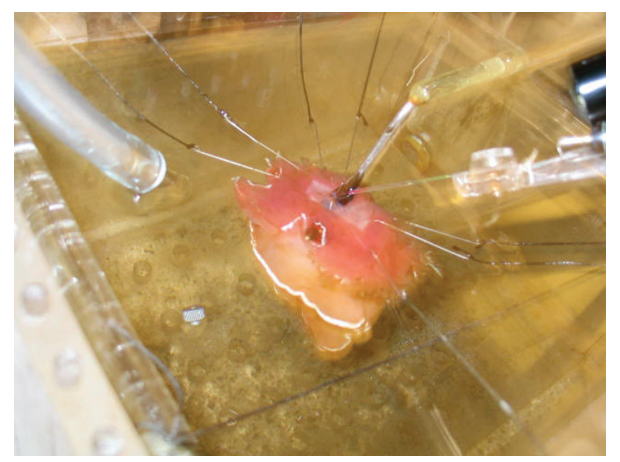

Figure 3: The water with food odor led through a hose to the animal.

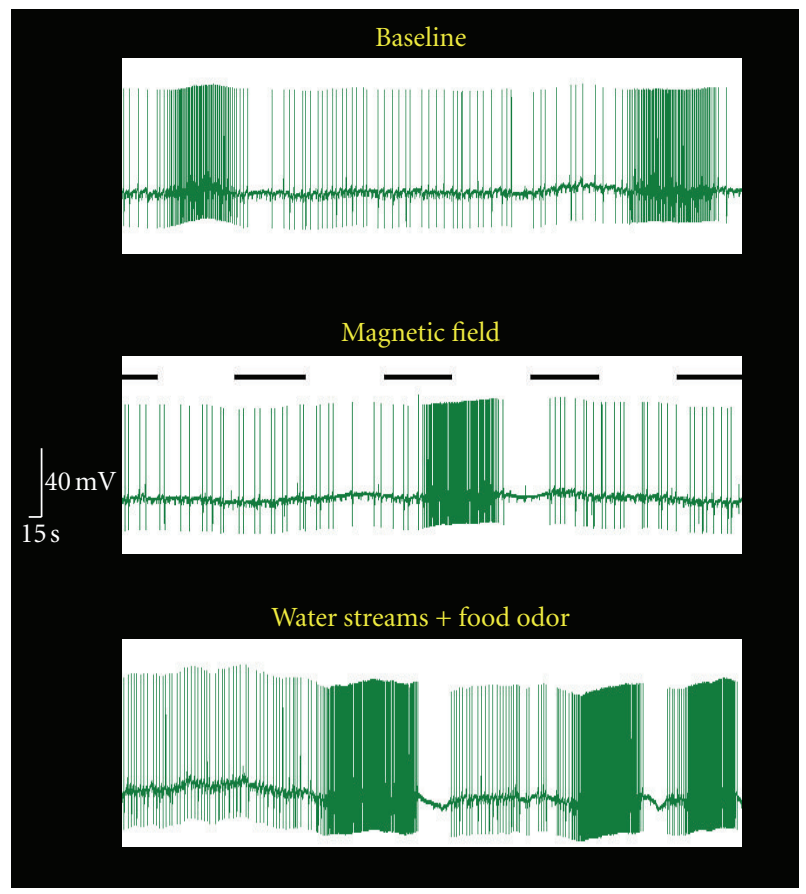

FIGURE 4: RPd7 activity during no stimuli, field changes, and water streams plus food odor stimulus.

\section{Results}

Figure 4 shows one of the recordings (RPd7 activity) with different stimulus. 500 seconds of each stimulus was compared here. The first one is the baseline (BL), where the action potential activity is recording without any stimuli.

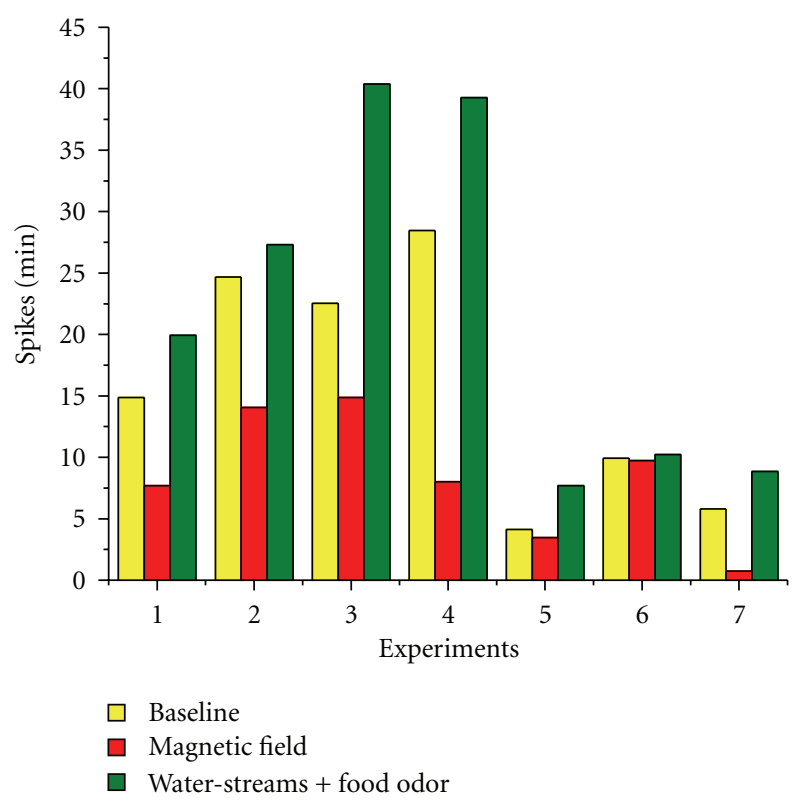

FIGURE 5: Intracellular recordings of Pd7 cells activity without stimuli and when stimulated with magnetic field changes or water streams plus food odor.

After that the magnetic field (MF) and the water streams with food odor stimulus (WS-FO) are shown. A decrease in the action potential frequency was observed when the magnetic field was changed and an increase when the water streams with food odor stimulus was applied.

Figure 5 shows the spikes per minute for each stimulus and baseline for the seven different experiments. In all experiments, a decrease in action potential frequency was observed during the magnetic field changes and an increase with the water streams plus food odor stimulus. The mean value and standard deviation are shown on Table 1. The statistical analysis shows significant difference between groups (BL versus MF: $P=0.029, \mathrm{BL}$ versus WS-FO: $P=0.036$, and MF versus WS-FO: $P=0.018$ ). There is a large difference in the action potential frequency of the 4 first cases and the 3 last ones (Figure 5). We observed that in the 4 first cases large animals $(12 \pm 2 \mathrm{~cm})$ were used, and small animals $(6 \pm$ $1 \mathrm{~cm}$ ) were used in the 3 last cases. The mean value and standard deviation of these two groups are shown on Table 1. The standard deviation decreases significantly when the animals are divided in two groups. These results point to a difference between animals size answer during the stimulus; 
it could be correlated with the animal necessity in different phases of life.

\section{Conclusion}

The changes in Pd7 activity indicate a response of enhanced electrical activity to water streams plus food odor stimulus. Pd7 activity can be excited by at least one of these stimuli. These results indicate an inverse relationship between magnetic orientation and feeding. Apparently two sensory pathways connected to Pd7 through different circuits. However, more studies are necessary to understand Pd7 function. For future studies, it is necessary to have more recording with food odor plus water streams stimulus considering animal phases of life to improve the statistic and recording with water streams only.

\section{Acknowledgments}

The authors acknowledges financial support from the Brazilian agencies $\mathrm{CNPq}$, CAPES and FAPERJ. I also thank Shaun D. Cain, James A. Murray, A. O. Dennis Willows, Natika Bock, and Friday Harbor Laboratories for animals and logistical support.

\section{References}

[1] A. O. D. Willows, "Behavioral acts elicited by stimulation of single, identifiable brain cells," Science, vol. 157, no. 3788, pp. 570-574, 1967.

[2] A. O. D. Willows, D. A. Dorsett, and G. Hoyle, "The neuronal basis of behavior in Tritonia. I. Functional organization of the central nervous system," Journal of Neurobiology, vol. 4, no. 3, pp. 207-237, 1973.

[3] S. Johnsen and K. J. Lohmann, "The physics and neurobiology of magnetoreception," Nature Reviews Neuroscience, vol. 6, no. 9, pp. 703-712, 2005.

[4] J. H. Wang, S. D. Cain, and K. J. Lohmann, "Identification of magnetically responsive neurons in the marine mollusc Tritonia diomedea," Journal of Experimental Biology, vol. 206, no. 2, pp. 381-388, 2003.

[5] J. H. Wang, S. D. Cain, and K. J. Lohmann, "Identifiable neurons inhibited by Earth-strength magnetic stimuli in the mollusc Tritonia diomedea," Journal of Experimental Biology, vol. 207, no. 6, pp. 1043-1049, 2004.

[6] S. D. Cain, J. H. Wang, and K. J. Lohmann, "Immunochemical and electrophysiological analyses of magnetically responsive neurons in the mollusc Tritonia diomedea," Journal of Comparative Physiology A, vol. 192, no. 3, pp. 235-245, 2006.

[7] I. R. Popescu and A. O. D. Willows, "Sources of magnetic sensory input to identified neurons active during crawling in the marine mollusc Tritonia diomedea," Journal of Experimental Biology, vol. 202, no. 21, pp. 3029-3036, 1999.

[8] R. C. Wyeth and A. O. D. Willows, "Odours detected by rhinophores mediate orientation to flow in the nudibranch mollusc, Tritonia diomedea," Journal of Experimental Biology, vol. 209, no. 8, pp. 1441-1453, 2006. 

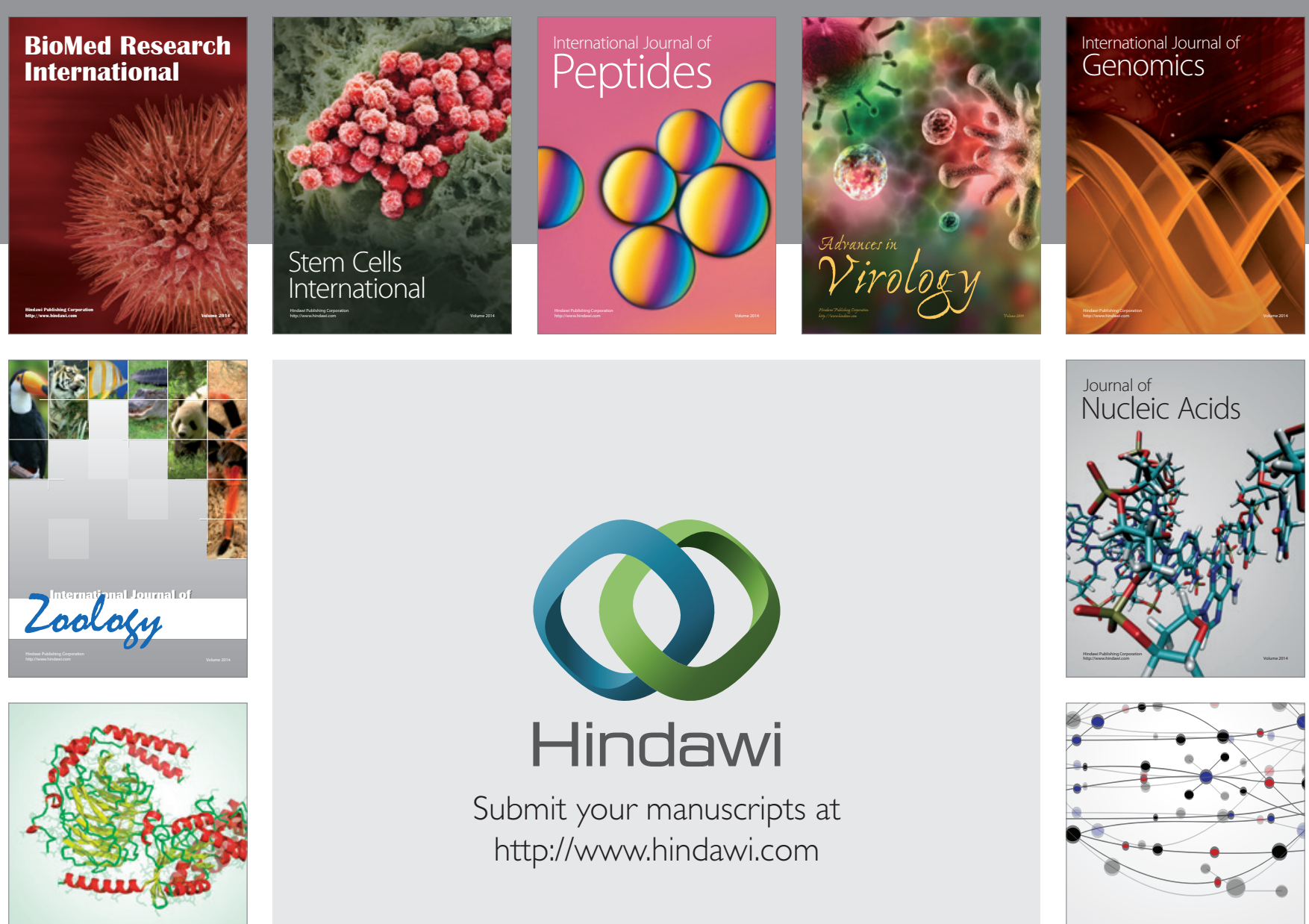

Submit your manuscripts at

http://www.hindawi.com

Signal ${ }^{\text {Jumal }}$ Transduction
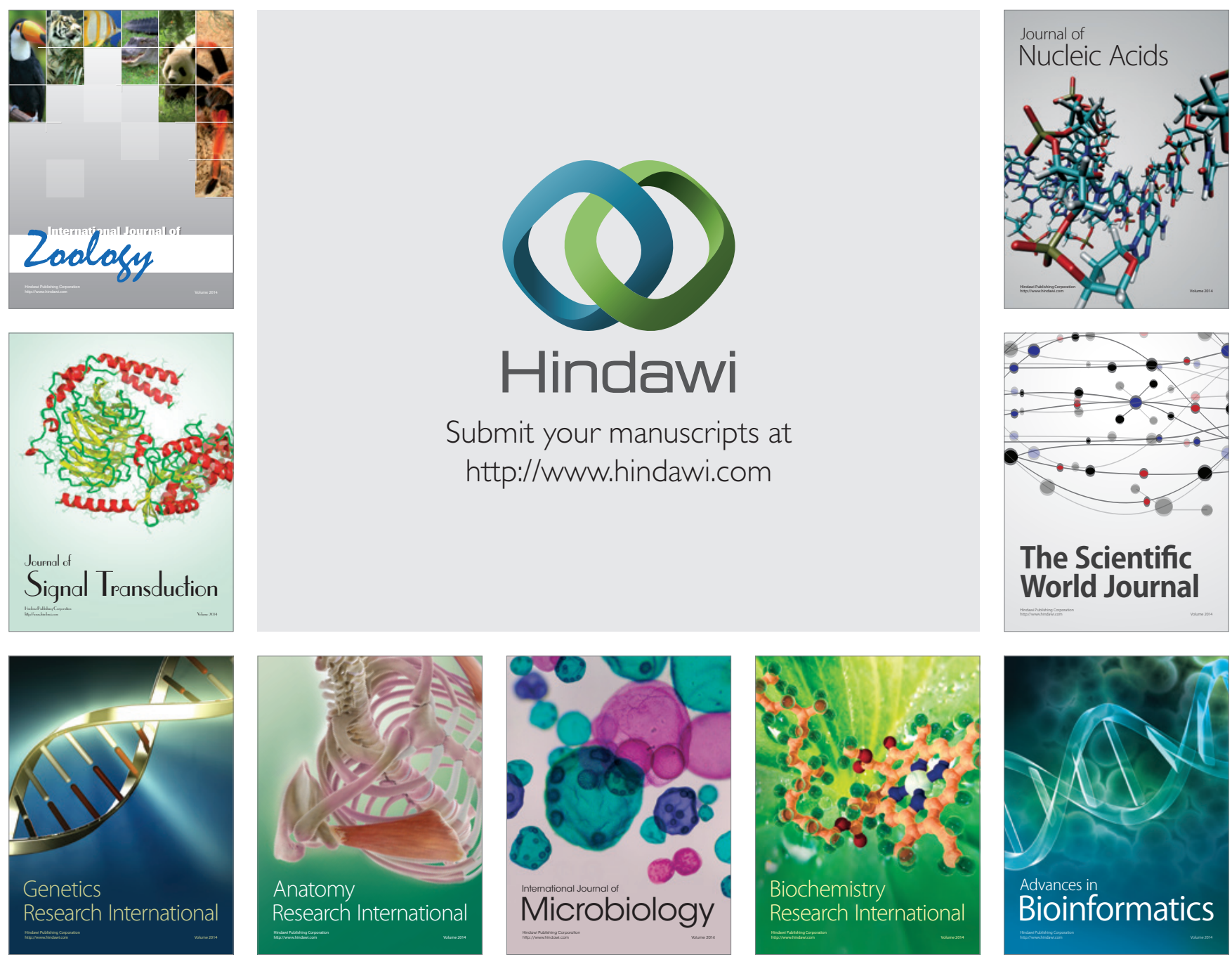

The Scientific World Journal
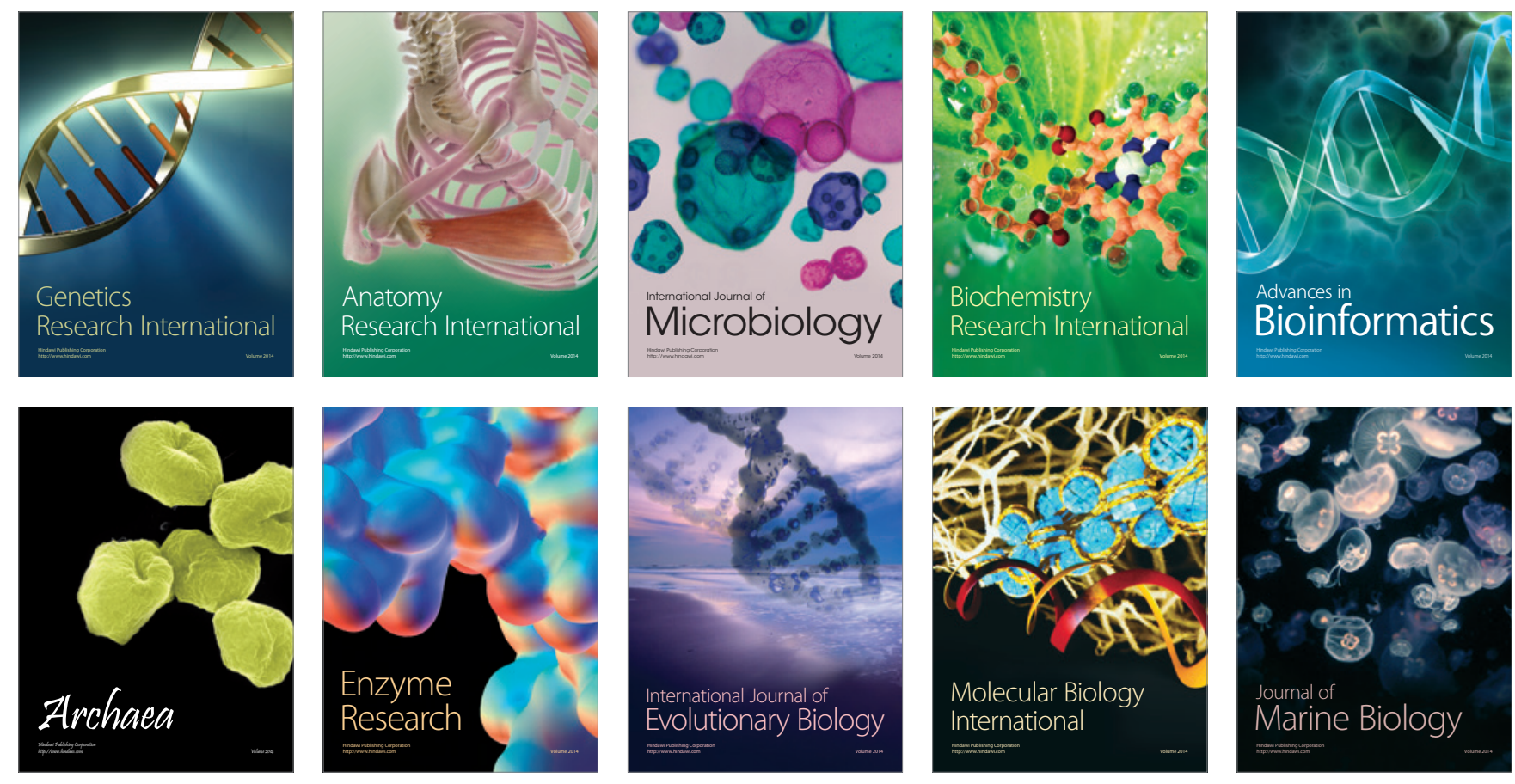